\title{
Female dental students' perceptions of patient safety culture: a cross sectional study at a middle eastern setting
}

\author{
Khaled Al-Surimi ${ }^{1,2}$, Haya AlAyadi ${ }^{3,4}$ and Mahmoud Salam ${ }^{5^{*}}$ (D)
}

\begin{abstract}
Background: Patient safety is an integral part of all health care specialties, including dentistry. Dental students are exposed to patient safety culture during their clinical training. The aim of this study was to evaluate the perception of female students enrolled in dental degrees and dental hygiene programs towards patient safety culture and to determine its associated factors at a Middle Eastern setting.

Methods: This is a cross sectional study, based on a self-administered, English language questionnaire distributed by convenience among female dental students enrolled in two major Colleges of dentistry in Riyadh, Saudi Arabia. Participants had fulfilled at least one year of clinical training. Sample characteristics included the specialty and years of clinical training. Student's perception was measured using the validated Safety Attitude Questionnaire (SAQ) that consists of 36 statements, distributed over six domains. Responses were rated on a five point Likert scale and the average positive response rate (APRR) was calculated. Binary logistic regression models were constructed to determine factors significantly associated with positive perceptions.
\end{abstract}

Results: The response rate of both student programs was 221/312(70.8\%). Students of dental sciences and dental hygiene programs were $133(60.2 \%)$ and $88(39.8 \%)$ respectively. Almost $42 \%$ of students were in their 1 st and 2nd years of clinical training. The APRR of: Team Work Climate domain was $54.4 \pm 28.0$, Safety Climate domain was 51.4 \pm 29.7, Job Satisfaction domain was $64.5 \pm 33.8$, Stress Recognition domain was 56.2 \pm 37.8 , Perceived Management Support domain was $50.7 \pm 37.7$, and Working conditions was $55.3 \pm 32.1$. Female students in their 3rd and 4th year of clinical were adj.OR $=2.3[1.3-4.0]$ times more likely to have positive perception regarding the team work climate domain when compared to 1 st and 2 nd year clinical students, $P=0.005$. At each of the six individual domains, the odds of having a positive perception were also significantly higher among dentistry students in comparison to dental hygiene students with a range of adj.OR 2.6-4.6.

Conclusions: Apparently patient safety is a concern among female dental students enrolled in dental degree and dental hygiene programs. This requires more attention from the staff, dental college's leadership/management, and faculty/students. Perception of dental students towards patient safety culture is expected to improve with the increase of clinical training.

Keywords: Perception, Patient safety, Culture, Dental, Students, Middle East

\footnotetext{
* Correspondence: mahmoudsalam@hotmail.com

${ }^{5}$ Science and Technology Unit, King Abdullah International Medical Research

Center, King Saud bin Abdulaziz University for Health Sciences, King

Abdulaziz Medical City, Ministry of National Guard - Health Affairs, PO 22490,

(Mail Code 1515), Riyadh 11426, Saudi Arabia

Full list of author information is available at the end of the article
}

(c) The Author(s). 2018 Open Access This article is distributed under the terms of the Creative Commons Attribution 4.0 International License (http://creativecommons.org/licenses/by/4.0/), which permits unrestricted use, distribution, and reproduction in any medium, provided you give appropriate credit to the original author(s) and the source, provide a link to the Creative Commons license, and indicate if changes were made. The Creative Commons Public Domain Dedication waiver (http://creativecommons.org/publicdomain/zero/1.0/) applies to the data made available in this article, unless otherwise stated. 


\section{Key points}

- Patient safety is an integral part of all healthcare specialties, including dentistry.

- Dental academicians and students should establish the foundations of a high quality culture of patient safety early in their training before graduation.

- Female dental students, especially dental hygiene students, are evidently concerned about patient safety.

- Perceptions of dental students towards the culture of patient safety are expected to improve while advancing in their clinical experience.

- Integrating patient safety culture within the dental curricula is necessary to assure patient safety and high quality of care in the dental care services.

\section{Background}

Patient safety is an integral part of any healthcare quality improvement system and the foundation of all other components of quality care [1, 2]. A 2007 Institute of Medicine (IOM) report stated that there should be a focus on the conceptual components of quality, not just the indicators to be measured. These components include safe, effective provision of healthcare that is patient-centered, timely, efficient, and equitable [2]. From evidence-based research, the World Health Organization (WHO) noted that at least 10\% of patients in developed countries have been injured because of an unsafe medical practice [3]. Comprehensive, equivalent data from developing and/or transitional economy countries is limited, but it is speculated that $2.5-18.4 \%$ of all admitted patients are subject to at least one type of adverse event [4]. WHO defined patient safety as the prevention of errors and adverse effects to patients associated with health care. Patient safety, and injuries caused by the healthcare sector, is of such great concern that WHO has established the World Alliance for Patient Safety initiative to address this problem globally [3]. In the Middle East, national and local data about patient safety is scarce; this warrants further research to determine the causes and extent of unsafe care [3].

The IOM has recommended that organizations address the culture of patient safety in their workplace [5]. A culture of patient safety is a system of care delivery that prevents harm to patients, built on safety that involves health care professionals, organizations and patients [6]. It is the product of individual and group values, attitudes, perceptions, competencies, and patterns of behavior [7]. For healthcare students and early career healthcare professionals, it is mandatory to understand and demonstrate appropriate knowledge and skills in the area of patient safety [8]. Most health and medical education curricula focus primarily on competency in medical knowledge, technical skills and judgment [9]. Few health faculties have introduced patient safety-specific teaching into their programs; others have included it as a core component of the curriculum. The WHO Patient Safety Curriculum Guide for Medical Schools, issued in 2009, concentrated on 11 topics based on the Australian Patient Safety Education Framework [10]. Research findings suggested that by introducing patient safety topics into the academic curriculum, students at colleges of health sciences are exposed to better practice, thus become safer healthcare practitioners of the future $[8,11]$.

There is an imperative need to assess students' perceptions about the principles of patient safety. Despite its importance, few dental schools (i.e. dental sciences and dental hygiene faculties) have incorporated topics about patient safety in their academic curricula $[8,12,13]$. This may be because morbidity, mortality and their financial impact in dental clinics is low compared to other healthcare settings [14]. One study described the development and evaluation of a three-day patient safety curriculum to advance knowledge, self-efficacy and system-based thinking among dental students; a model previously implemented by Johns Hopkins School of Medicine in the USA. After completing the course, students showed significant improvements in self-efficacy and safety skills [15].

The culture of patient safety is affected by several factors such as the organizational aspects (safety climate and morale), work environment factors (staffing levels and managerial support), team factors (teamwork and supervision), and staff factors (overconfidence and being overly self-assured), that all should be assessed comprehensively [7]. The establishment and maintenance of a culture of patient safety has seldom been studied among the population of female dentists in Middle Eastern countries such as Saudi Arabia. In Saudi Arabia, university faculties are segregated by gender. The first college of dentistry in Saudi Arabia was established in 1975, but admission was restricted to male students until 1978 [16]. The increasing population in Saudi Arabia has led to a demand for more dental clinics, yet not all dental colleges in this country enrol female dental students. As of December 2017, the number of licensed dentists (specialized and non-specialized) in Saudi Arabia, (of all nationalities) was 93,966, with only 25,249 (26.9\%) being of Saudi origin [17]. Female Saudi dentists comprised only $1,438(8.5 \%)$ of the dental workforce [18]. Therefore, the aim of this study was to evaluate the perceptions of female dental degrees and dental hygiene students about the culture of patient safety and its associated factors in a Middle Eastern setting.

\section{Methods}

This cross-sectional study was based on a self-administered survey conducted at King Saud bin Abdulaziz University-College of Dentistry and Riyadh Private Dental College 
between November 2016 and January 2017. The study was approved by the Institutional Review Board of the Saudi Ministry of National Guard - Health Affairs (protocol number RC13/036), and permission was received from the administrators of both colleges.

Using a convenience sampling method, an envelope containing a cover letter, written informed consent form and English language questionnaire was distributed in person to all students of dental sciences and dental hygiene programs enrolled in the targeted settings. An anticipated sample size of 277 was calculated, based on an assumed response rate of $50 \%$ favorable positive perceptions, a $95 \%$ confidence level and a $6 \%$ margin of error.

Participants were included if they were Saudi, female undergraduate students of dental sciences (six year program and one year internship) or dental hygiene (four year program), who had completed at least one full year of training in dental clinics (working on real patients) and supervised by mentors. Students of dental sciences start their clinical training at their 4rth academic year, while dental hygiene program students start their clinical training at their $2^{\text {nd }}$ academic year. Students who had not started working on real patients (e.g., those using manikin simulation training) were excluded. This ensured that study participants had experienced real working environments and would therefore be able to report their perceptions towards the culture of patient safety within those environments.

The cover letter explained the study objectives and informed students that their participation was voluntary. Students of both programs were assured that the data collected would be used only for research purposes, thus maintaining their privacy and the confidentiality of their feedback. The informed consent form stated participants' right to withdraw from the study without constraint at any time. Study participants responded within one to two days after receiving the survey. Students who failed to return the distributed surveys beyond the second day were not reminded to fill them out in order to avoid participation bias, so they were dropped out.

The questionnaire included questions about students' characteristics (age, type of college, specialty, and years of clinical training). Clinical training was categorized into two groups. Group one were students of dental sciences and dental hygiene program who both fulfilled their $1^{\text {st }}$ and $2^{\text {nd }}$ year of clinical training versus group two who were dental science students who fulfilled their $3^{\text {rd }}$ and $4^{\text {th }}$ year of clinical training with dental hygiene students who fulfilled their $3^{\text {rd }}$ year). The outcome characteristics were measured using the Safety Attitude Questionnaire (SAQ) that was developed by the Foundation and Agency for Healthcare Research and Quality $[7,19,20]$. It was designed to assess six domains of safety climate: 'Teamwork Climate' (six statements), 'Job Safety Climate' (eight statements), 'Job Satisfaction' (five statements), 'Stress Recognition' (four statements), 'Perceptions of Management' (six statements), and 'Working Conditions' (seven statements). Responses were rated on a five-point Likert scale ('strongly disagree,' 'disagree,' 'neutral,' 'agree,' 'strongly agree'). The original version of the SAQ was customized to be more appropriate for dental students. Minor modifications included using the terms 'dental clinical area' instead of 'hospital clinical area', and 'student' instead of 'nurse'. The modified version of SAQ was piloted among a sample of 23 students from both colleges. Internal consistency testing yielded Cronbach's alpha values between 0.6 and 0.81 across the six domains (Additional file 1).

SPSS version 25 (IBM, NY, USA) was used for data analysis. Descriptive statistics of categorical variables such as student characteristics were presented as frequencies and percentages. For each SAQ statement, 'strongly disagree' and 'disagree' responses were grouped as a 'negative' response, while 'agree' and 'strongly agree' answers were grouped as 'positive' responses. These were presented as frequencies and percentages.

To calculate the average positive response rate (APRR), individual SAQ statements were rated as 0 for those who responded with 'strongly disagree,' 'disagree' or 'neutral', and as 1 for those who responded with 'agree' or 'strongly agree'. APRR was then calculated by dividing the number of positive perception statements by the total number of statements per domain. The APRR of all students across individual domains was then presented as mean \pm SD. Adjusted by the academic specialty, students with mean APRR scores of above 50 (above neutral response) for any specific domain were counted as having a positively perceived domain, while those with scores of 50 and below were counted as having a negatively perceived domain [21]. However, some studies such as Nordén-Hägg et al, adopted the cut-off point of percentage mean score $\geq 75$ as indicator of positive responses to SAQ statements [22]. The overall score of SAQ domains was neither investigated in this study nor in previous literature, as the value of this tool is in its ability to assess and recommend improvements in the safety culture at its six specific targets or domains [23].

Pearson's Chi-square test was used to identify higher rates of positive perception across student characteristics. Pearson's correlation was conducted to describe the relationship between various SAQ domains. A series of binary logistic regression models was constructed to determine factors significantly associated with positive perceptions and the adjusted odds ratio for individual SAQ domains was presented. The level of significance was set after applying the Holm-Bonferroni correction at $P$-value $<0.04$. 


\section{Results}

\section{Student and outcome characteristics}

Of the 312 questionnaires distributed, 221 questionnaires were completed and returned. Response rate was $(60.2 \%, n=133)$ among students of dental sciences, and $(39.8 \%, n=88)$ among students of the dental hygiene program. The mean \pm standard deviation of age was comparable in both specialty groups, with average in both $21.9 \pm$ 1.8 years. One hundred and sixty-five students (74.7\%) were enrolled at King Saud bin Abdulaziz University (public sector) among whom 97(58.8\%) were students of dental sciences. Among the 56 (25.3\%) students enrolled in the private Riyadh Dental College, 36(64.3\%) were students of dental sciences. The sample contained $92(41.6 \%)$ students in their first or second year of clinical training, and $129(58.4 \%)$ were in their third or fourth year (mean: $2.6 \pm 0.9$ years), See Table 1. Equal distribution between students of dental sciences and dental hygiene was observed throughout the clinical training years.

Responses to individual SAQ statements are presented in Table 2. For the 'Teamwork Climate' domain, the APRR was 54.4 \pm 28.0 , with the highest positive response observed when the students were asked whether or not "it is easy to ask questions if something is not understandable". In the 'Safety Climate' domain, the APRR was 51.4 \pm 29.7 , and the highest positive response was observed when the students were asked whether they "received appropriate feedback about their performance" (134; 60.6\%). For the 'Job Satisfaction' domain, the APRR was $64.5 \pm 33.8$, and the highest positive response was noted in response to the statement asking whether the student "liked her specialty" (167; 75.5\%). In the 'Stress Recognition' domain, the APRR was $56.2 \pm 37.8$, and the highest positive response was to the statement, "I am less effective when I feel fatigued" (134; 60.6\%). In terms of the 'Perceived Management Support' domain, the APRR was $50.7 \pm 37.7$, and the highest positive

Table 1 Sample and outcome characteristics

\begin{tabular}{ll}
\hline & $N=221(70.8 \%)$ \\
\hline Age (mean \pm SD) & $21.9 \pm 1.8$ \\
Type of college & \\
Private & $56(25.3)$ \\
Public & $165(74.7)$ \\
Specialty & \\
Dental sciences & $133(60.2)$ \\
Dental hygiene & $88(39.8)$ \\
Years of clinical training & \\
One & \\
Two & $36(16.3)$ \\
Third & $56(25.3)$ \\
Four & $85(38.5)$ \\
Mean \pm SD & $44(19.9)$ \\
\hline
\end{tabular}

$n$ frequency, \%, percentage, SD standard deviation response was to whether "the clinical supervisor was doing a good job" (134; 60.6\%). Finally, the APRR of the 'Working Conditions' domain was $55.3 \pm 32.1$, with 138 (62.4\%) positively responding that "students had good collaborations with their colleagues". Analysis of the interrelationships between the six SAQ domains revealed that all were positively and significantly correlated with each other (Table 3).

Factors associated with positive perceptions of SAQ domains From the sample of female dental students enrolled in both specialties in our study, there were significantly more negative perceptions within the domain of 'Safety Climate' $(131 ; 59.3 \%)$ than those with positive perceptions (90; 40.7\%, $P=0.006)$. Significantly more students had positive perceptions within the 'Job Satisfaction' (145, 65.6\%) and 'Working Condition' domains (126, 57\%) than negative perceptions $(P<0.001$ and $P=0.037$, respectively). Students in their third or fourth years of clinical training $(75,58.1 \%)$ had significantly more positive perceptions within the 'Teamwork Climate' domain than students in their first or second years (33, 35.9\%, $P=0.001)$. There were no statistically significant differences between responses to statements in any domain in terms of type of college.

The highest positive response rate among students of dental degree was observed at job satisfaction (78.9\%) and working conditions (66.2\%) domains which were significantly higher than students of dental hygiene, (45.5\%, $P<0.001)$ and $(43.2 \%, P=0.001)$ respectively. The least positive response rates were observed among students of dental hygiene at the safety climate $(25.0 \%)$ and perceived management support (28.4\%), compared to students of dental sciences who had higher positive response rates, $(51.1 \%, P<0.001)$ and $(55.6 \%, \mathrm{P}<0.001)$. All in all, women studying on academic dental specialty had significantly more positive perceptions across all six domains compared with dental hygiene students (Table 4).

A series of logistic regression analyses were constructed to adjust for any possible confounding effect between the years of clinical training and dental specialty. Female students in their third or fourth years of clinical training were 2.3 (CI: 1.3-4.0) times more likely to have a positive perception of the 'Teamwork Climate' than junior students (adjusted $P=0.005$ ). For each of the six individual domains, students of dental sciences were significantly more likely to have positive perceptions compared with dental hygiene students (range of adjusted OR: 2.6-4.6) (Table 5).

\section{Discussion}

Female dentists' perception towards the culture of patient safety hasn't been previously investigated. Two studies 
Table 2 Responses to the Safety Attitude statements

\begin{tabular}{|c|c|c|c|}
\hline & $\begin{array}{l}\text { Negative } \\
n(\%)\end{array}$ & $\begin{array}{l}\text { Neutral } \\
n(\%)\end{array}$ & $\begin{array}{l}\text { Positive } \\
n(\%)\end{array}$ \\
\hline \multicolumn{4}{|l|}{ Team work climate (Cronbach's $a=0.60)$} \\
\hline 1. Students input is well received in this clinical area. & 18(8.0) & $98(44.5)$ & 107(48.5) \\
\hline 2. In this dental clinic, it is difficult to speak up if I perceive a problem with patient care. & $84(38.0)$ & 63(28.5) & $74(33.5)$ \\
\hline $\begin{array}{l}\text { 3. Disagreements in this clinical area are resolved appropriately (i.e., not who is right, but } \\
\text { what is best for the patient). }\end{array}$ & $33(14.9)$ & 88(39.8) & 100(45.3) \\
\hline 4. I have the support I need from other personnel to care for patients. & 18(8.1) & $61(27.6)$ & 142(64.3) \\
\hline 5. It is easy for students here to ask questions when there is something that they do not understand. & 25(11.4) & $40(18.1)$ & 156(70.5) \\
\hline 6. The supervisors and students here work together as a well-coordinated team. & 29(13.1) & $58(26.2)$ & 103(60.7) \\
\hline Average positive response rate (Mean $\pm \mathrm{SD})$ & $54.4 \pm 28.0$ & & \\
\hline \multicolumn{4}{|l|}{ Safety climate (Cronbach's $a=0.75)$} \\
\hline 7. I would feel safe being treated here as a patient. & $45(20.4)$ & 75(33.9) & 101(50.7) \\
\hline 8. Medical errors are handled appropriately in this clinical area. & 20(9.1) & $76(34.4)$ & 125(56.5) \\
\hline 9. I know the proper channels to direct questions regarding patient safety in this clinical area & 23(10.4) & $81(36.7)$ & 117(52.9) \\
\hline 10. I receive appropriate feedback about my performance. & 25(11.3) & $62(28.1)$ & 134(60.6) \\
\hline 11. In this dental clinic, it is difficult to discuss errors. & $85(38.5)$ & $67(30.3)$ & $69(31.2)$ \\
\hline 12. I am encouraged by my colleagues to report any patient safety concerns I may have & 11(5.0) & $81(36.7)$ & $129(58.3)$ \\
\hline 13. The environment in this dental clinic makes it easy to learn from the errors of others. & 30(13.6) & $67(30.3)$ & 124(56.1) \\
\hline 14. My suggestions about safety would be acted upon if I expressed them to management. & $27(12.2)$ & 101(45.8) & $93(42.0)$ \\
\hline Average positive response rate (Mean $\pm \mathrm{SD})$ & $51.4 \pm 29.7$ & & \\
\hline \multicolumn{4}{|l|}{ Job satisfaction (Cronbach's $a=0.76$ ) } \\
\hline 15. I like my specialty & 19(8.7) & 35(15.8) & 167(75.5) \\
\hline 16. Practicing here is like being part of a large family. & 24(10.9) & $56(25.3)$ & $141(63.8)$ \\
\hline 17. This is a good place to practice. & 35(15.8) & $55(24.9)$ & 131(59.3) \\
\hline 18. I am proud to practice in this dental clinic & $34(15.4)$ & $45(20.4)$ & 142(64.2) \\
\hline 19. Ethics in this dental clinic is high. & $8(9.5)$ & 68(30.8) & 132(59.7) \\
\hline Average positive response rate (Mean \pm SD) & $64.5 \pm 33.8$ & & \\
\hline \multicolumn{4}{|l|}{ Stress recognition (Cronbach's $a=0.76$ ) } \\
\hline 20. When my workload becomes excessive, my performance is impaired. & 25(11.4) & $77(34.8)$ & 119(53.8) \\
\hline 21. I am less effective at work when fatigued. & 19(8.6) & 68(30.8) & 134(60.6) \\
\hline 22. I am more likely to make errors in tense or hostile situations & $32(14.5)$ & $58(26.2)$ & 131(59.3) \\
\hline 23. Fatigue impairs my performance during emergency situations. & $41(18.6)$ & $67(30.3)$ & 113(51.1) \\
\hline Average positive response rate (Mean $\pm \mathrm{SD})$ & $56.2 \pm 37.8$ & & \\
\hline \multicolumn{4}{|l|}{ Perceived management support (Cronbach's $a=0.81$ ) } \\
\hline 24. Clinical management supports my daily efforts & 15(6.8) & $98(44.3)$ & 108(48.9) \\
\hline 25. Clinical management doesn't knowingly compromise patient safety & 30(13.6) & $89(40.3)$ & 102(46.1) \\
\hline 26. Clinical supervisor is doing a good job & $31(14.5)$ & $55(24.9)$ & 134(60.6) \\
\hline 27. Problem personnel are dealt with constructively by our clinical units & $21(9.5)$ & 97(43.9) & 103(46.6) \\
\hline 28. I get adequate, timely info about events that might affect my work & $35(15.9)$ & $78(35.3)$ & 108(48.8) \\
\hline 29. The levels of students in this dental clinic are sufficient to handle the number of patients. & $37(16.7)$ & $67(30.3)$ & 117(53.0) \\
\hline Average positive response rate (Mean $\pm \mathrm{SD})$ & $50.7 \pm 37.7$ & & \\
\hline \multicolumn{4}{|l|}{ Working conditions (Cronbach's $a=0.77$ ) } \\
\hline 30. This dental clinic does a good job of training new personnel.(e.g. students or staff) & 29(23.1) & $60(27.1)$ & 132(59.8) \\
\hline 31. All necessary information for diagnostic and therapeutic decisions is routinely available to me. & $16(7.3)$ & 73(33.0) & 132(59.7) \\
\hline 32. Trainees in my discipline are adequately supervised. & $6(9.5)$ & 68(30.8) & 132(59.7) \\
\hline
\end{tabular}


Table 2 Responses to the Safety Attitude statements (Continued)

\begin{tabular}{|c|c|c|c|}
\hline & $\begin{array}{l}\text { Negative } \\
n(\%)\end{array}$ & $\begin{array}{l}\text { Neutral } \\
n(\%)\end{array}$ & $\begin{array}{l}\text { Positive } \\
n(\%)\end{array}$ \\
\hline 33. I experience good collaboration with students in this clinical area. & 13(5.9) & 70(31.7) & $138(62.4)$ \\
\hline 34. I experience good collaboration with dental staff in this dental clinic. & 24(10.8) & 73(33.0) & 124(56.2) \\
\hline 35. I experience good collaboration with booking staff in this dental clinic. & $62(28.1)$ & 74(33.5) & $85(38.4)$ \\
\hline 36. Communication barriers that lead to delays in delivery of care are common. & 112(50.6) & 76(34.5) & $33(14.9)$ \\
\hline Average positive response rate (Mean $\pm \mathrm{SD})$ & $55.3 \pm 32.1$ & & \\
\hline
\end{tabular}

$n$ frequency, \% percentage

have evaluated it among health care workers, with their targeted sample having predominant female gender distribution, $79 \%$ and $90 \%$ respectively $[24,25]$. For instance, the positive response rates of the six dimensions among Chinese health care workers were as follows: Teamwork Climate: 59.31\%; Safety Climate: 54.09\%; Job Satisfaction: 54.63\%; Working Conditions: 46.69\%; Recognition of Management: 45.97\%; and Stress Recognition: $20.80 \%$, all of which were lower than 60\% [24]. Another study conducted among Danish health care workers found that the positive response rates ranged from $42.6 \%$ for perception of unit management to $64.8 \%$ for teamwork climate [25]. Both studies revealed different results compared to findings in this study, where the range of positive response rate was between $50.7 \%$ and $64.7 \%$ (lowest being the perceived management support and highest the satisfaction domain). This can be probably attributed to the difference in the scope of practice.

Students of dental sciences and dental hygiene are aware that their profession in future has its share of clinical and psychological risks to the patient, such as wrong tooth extraction, bleeding, allergy, infection and others $[26,27]$. Therefore, authors of this study believe that the Safety Attitude Culture questionnaire used in this setting touched upon the students' perceptions of the culture of patient safety at an early stage within a training environment, at a deeper personal level, and before graduation.
It can be hypothesized that the moderately low positive responses to statements in our SAQ questionnaire could be attributed to students' limited exposure to real life clinical scenarios. It is well known that early clinical experience (field training) helps students develop appropriate attitudes towards their future practice; nevertheless it is important for students to become orientated with the culture of patient safety at early stages of their career [28]. Students might also have had a limited opportunity to associate what has been learned in classes with the reality of the clinical profession [29]. Lesser positive responses might also be attributed to differences in the scope of practice between students of dental sciences and dental hygiene [30]. This implies that patient care and safety protocols differ between the academic courses of both student groups and therefore, their perception will also differ throughout the six domains of patient safety culture.

Preceptors who facilitate communication with their students and maximize teaching time in the clinic actually help their students to approach patient care in a more positive and problem-solving manner [31]. One study reported that ethical disagreements are not common in dentistry, and if they do occur, they are easily resolved [32]. There is no doubt that unresolved conflicts can be stressors, but students tend to be more lenient and accommodating of disagreements than employees.

Table 3 Pearson's correlation between the average positive response rates of various SAQ domains

\begin{tabular}{|c|c|c|c|c|c|}
\hline & Team work climate & Safety climate & Job satisfaction & Stress recognition & Management support \\
\hline \multirow[t]{2}{*}{ Safety climate } & 0.647 & & & & \\
\hline & $P<0.001^{*}$ & & & & \\
\hline \multirow[t]{2}{*}{ Job satisfaction } & 0.569 & 0.666 & & & \\
\hline & $P<0.001^{*}$ & $P<0.001^{*}$ & & & \\
\hline \multirow[t]{2}{*}{ Stress recognition } & 0.167 & 0.326 & 0.371 & & \\
\hline & $P=0.013^{*}$ & $P<0.001^{*}$ & $P<0.001^{*}$ & & \\
\hline \multirow[t]{2}{*}{ Perceived management support } & 0.550 & 0.714 & 0.614 & 0.345 & \\
\hline & $P<0.001^{*}$ & $P<0.001^{*}$ & $P<0.001^{*}$ & $P<0.001^{*}$ & \\
\hline \multirow[t]{2}{*}{ Working conditions } & 0.458 & 0.670 & 0.569 & 0.353 & 0.714 \\
\hline & $P<0.001^{*}$ & $P<0.001^{*}$ & $P<0.001^{*}$ & $P<0.001^{*}$ & $P<0.001^{*}$ \\
\hline
\end{tabular}

$P P$-value, ${ }^{*}$ statistically significant at $<0.05$ 
Table 4 Positive perception rates of various SAQ domains across students' characteristics

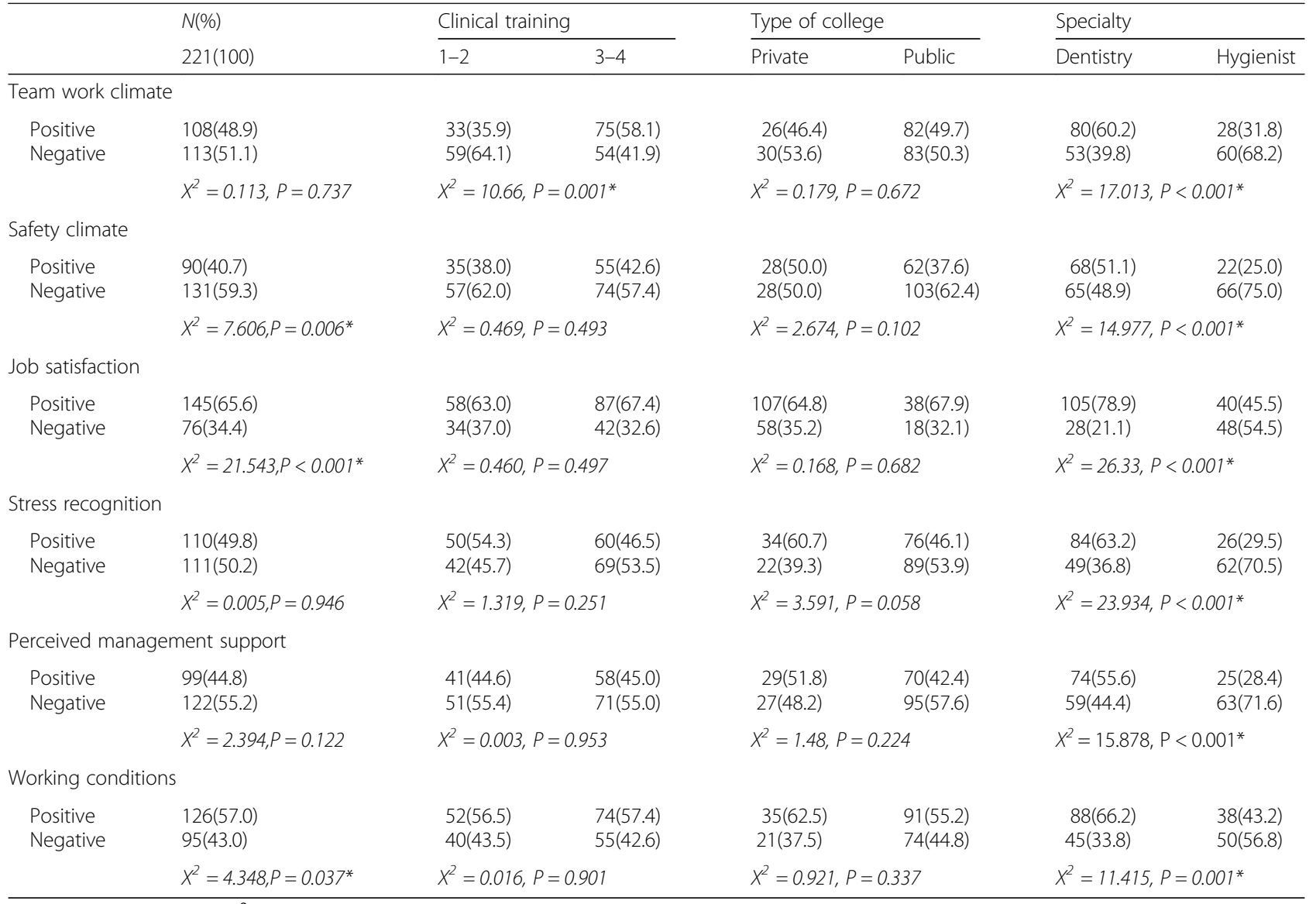

$n$ frequency, \% percentage, $X^{2}$ Pearson Chi-square, $P$-value, ${ }^{*}$ significant at $P<0.04$

Table 5 Factors associated with the positive responses of SAQ domains

\begin{tabular}{|c|c|c|}
\hline & $\begin{array}{l}\text { Clinical training (years) } \\
1-2^{0} ; 3-4^{1}\end{array}$ & $\begin{array}{l}\text { Specialty } \\
\text { Hygiene }^{0} \text {; Dentistry }\end{array}$ \\
\hline & adj.OR [95\% Cl] & adj.OR [95\% Cl] \\
\hline \multirow[t]{2}{*}{ Team work climate } & $2.3[1.3-4.0]$ & $3.0[1.7-5.4]$ \\
\hline & Adj. $P=0.005^{*}$ & Adj. $P<0.001^{*}$ \\
\hline \multirow[t]{2}{*}{ Safety climate } & $1.0[0.6-1.9]$ & $3.1[1.7-5.7]$ \\
\hline & Adj. $P=0.875$ & Adj. $P<0.001^{*}$ \\
\hline \multirow[t]{2}{*}{ Job satisfaction } & $1.0[0.5-1.8]$ & $4.5[2.5-8.2]$ \\
\hline & Adj. $P=0.974$ & Adj.P $<0.001^{*}$ \\
\hline \multirow[t]{2}{*}{ Stress recognition } & $0.6[0.3-1.0]$ & $4.6[2.5-8.3]$ \\
\hline & Adj. $P=0.052$ & Adj. $P<0.001^{*}$ \\
\hline \multirow{2}{*}{$\begin{array}{l}\text { Perceived management } \\
\text { support }\end{array}$} & $0.86[0.5-1.5]$ & $3.2[1.8-5.8]$ \\
\hline & Adj. $P=0.606$ & Adj. $P<0.001^{*}$ \\
\hline \multirow[t]{2}{*}{ Working conditions } & $0.9[0.5-1.6]$ & $2.6[1.5-4.6]$ \\
\hline & Adj. $. P=0.723$ & $\operatorname{Adj} . P=0.001^{*}$ \\
\hline
\end{tabular}

*Statistically significant at $P<0.05 ;{ }^{0}$ : reference group, ': compared group, OR: odds ratio, Cl: confidence interval; $\mathrm{Adj}=$ adjusted
Findings in this study suggest that there might be deficiencies in the interpersonal relationships between students and supervisors, or between students and clinicians as perceived by the students. In clinical professions, the leading causes of errors that compromise patient safety are lack of communication and poor coordination of care between team members [33]. Dental students should acknowledge the fact that patient-centered care is crucial, so clinical training is important in sculpting the students' future work relationships to creating a safe work climate.

Adverse events caused by errors are rare, yet they are inevitable in any clinical practice, so reporting them is a major patient safety issue [34]. Students of dental sciences and dental hygiene in this study might perceive that committing errors reflects poorly on their personal performance, whereas in fact, there may be other reasons system-related errors, for example. Besides being a crucial preventive measure, reporting errors to mentors is a good learning opportunity for other students. Therefore, it has been recommended that, during the course of their training, these students should be better prepared for communication and reporting challenges associated with errors in clinical practice [34]. 
At the student level, satisfaction can be understood as being a measure of the students' true interest in their pursuit of the dental profession. Authors speculate that students of dental sciences and dental hygiene who are dissatisfied with their future career will be more likely to jeopardize patient safety across all domains of SAQ. In other words, students of both specialties in this setting believed that dissatisfied dentists might seldom report errors which affects patient safety, disturb working relationships with colleagues, increase stress, and are less in productivity. Students of dental hygiene had less positive perceptions in terms of the 'Job Satisfaction' domain, probably because of the mismatch in scope of practice, or wages after graduation. In contrast, one study found that students' motivation to become a dental hygienist was significantly higher than those following an academic route, because they enroll in this program directly after graduating from high school [35].

Students of both specialties in this setting perceived the future workload as a potential impairment of their performance and cause of fatigue. Students of dental sciences, in particular, are more prone to stress because of the academic and financial burdens associated with this type of training, and the effects of continual clinical supervision [36]. However, a positive response on this domain might be attributed to the Hawthorne effect, whereby students might not admit to anything that might affect their grades. Therefore, the responses given to this domain, and probably other domains, might not accurately reflect the students' real perceptions, and they might change when they take on full-time jobs. Compared with students of dental hygiene, students of dental sciences require more advanced practice and greater responsibility [37], therefore stress is expected to be higher. However, our study found that students of dental sciences had more positive perceptions than students of dental hygiene, indicating that the first group is better at coping with future complex work scenarios.

Some might speculate that it is too early to question students of dental hygiene and dental sciences about their perceptions of managerial support. In a similar previous study, students of dentistry reported highly positive perceptions of 'organizational learning,' 'continuous improvement' and 'teamwork' [38]. Although after graduation most dentists work independently at private clinics, this is not the case with dentists employed in healthcare facilities. In this study, there was a lack of awareness on the managerial role in the clinical training setting, because students of both specialties are expected to report directly to their academic supervisors rather than the hospital management. Exposing these students to clinical management at an early stage of their training helps them to refine their interpersonal and communication skills, and facilitates their assimilation into a real-life work environment upon graduation and employment [39].
Students usually have friendly relationships with clinic employees. They are eager to learn and work, and regularly receive support from other members of staff. It was reported that after graduation and employment, the perceptions of the culture of patient safety among graduates of dental professionals' improves further [38]. Therefore, this stage is critical: students placed in clinical training environments where there is a lack of support often lag behind in terms of skill development, and may even withdraw from education [40].

One study noted a medical-dental discrepancy in students' perceptions and views towards the culture of patient safety and healthcare quality. This was justified by admitting that there are fundamental differences in the work and workflows of dental clinics versus medical clinics. Another justification was that, in terms of the culture of patient safety, medical students may have had a greater level of maturity than dental students, simply because there was a delay in the incorporation of these recommendations into dental curricula and practice at an earlier stage of career development.

Few limitations were encountered in this study. Associations between perceptions of the culture of patient safety culture, and other factors such as male gender, academic performance, and dental assistants have yet to be tested. Finally, recruiting students enrolled in dentistry colleges from other geographical regions might have boosted the generalizability and representativeness of the sample.

\section{Conclusions}

Female students of dental sciences and dental hygiene are evidently concerned about patient safety, and this requires greater attention by the faculty, especially among dental hygiene students. Perceptions of dental students of both specialties towards the culture of patient safety are expected to improve with increasing years of clinical experience.

\section{Recommendations}

Patient safety is everyone's responsibility, so both dental academicians and students should establish the foundations of a high quality culture of patient safety early in their training. Determining students' needs in terms of quality assurance/improvement and patient safety should be followed by efforts to improve their knowledge, understanding and awareness of these matters, thus establishing the foundation to a true culture of patient safety [41]. A considerable level of awareness, knowledge, skills and concern for patient safety is highly recommended to ensure that dental students adopt optimal levels of quality of dental healthcare in future. Dental college faculties and members of management are advised to integrate the principles of patient safety into the academic curricula, similar to what has previously been adopted by 
medical schools. These principles can be incorporated in national rules, regulations and guidelines, especially for high-risk dental procedures. The number of female students who seek enrollment in dentistry is rising to keep up with market's demand. Although there are currently no restrictions on female education, further studies are needed to explore the perceived willingness of females to pursue dental education, within the scope of culture of patient safety and history of gender-based restricted education.

\section{Additional file}

Additional file 1: Safety Attitude Questionnaire Survey. The Safety

Attitude Questionnaire (SAQ) for dental students. (DOC $114 \mathrm{~kb}$ )

\section{Abbreviations}

APRR: Average positive response rate; IOM: Institute of Medicine; OR: Odd Ratio; SAQ: Safety Attitude Questionnaire; WHO: World Health Organization

\section{Acknowledgements}

This study was approved and monitored by King Abdullah International Medical Research Center, King Saud bin Abdulaziz University for Health Sciences, Riyadh, Saudi Arabia. The authors would like to thank the Research Office and the Institutional Review Board for their tremendous support.

\section{Funding}

This research did not receive any specific grant from funding agencies in the public, commercial, or not-for-profit sectors.

\section{Availability of data and materials}

The datasets generated and/or analyzed during the current study are not publicly available as per the policies of the Institutional Review Board of the Ministry of National Guard Health Affairs, but are available from the corresponding author on reasonable request.

\section{Authors' contributions}

All authors conceptualized and designed the study. KS supervised the conduct of the study and data collection. HAA undertook the recruitment of subjects and managed the data. KS was accounted for the quality control. MS provided statistical advice on study design, data analysis and correspondence. All authors drafted the manuscript, and contributed substantially to its revision as submitted and agree to be accountable for all aspects of the work. All authors meet the ICMJE criteria for authorship. All authors read and approved the final manuscript.

\section{Authors' information}

- Dr. Kaheld AI-Surimi: is an associate professor of Public Health and Health Systems Management at King Saud bin Abdulaziz University for Health Sciences

- Ms. Haya AlAyadi: was a master student in the Public Health and Health Informatics at King Saud bin Abdulaziz University for Health Sciences, and now she is a PhD student at the Division of Population and Patient Health, King's College London Dental Institute at Guy's, King's College and St. Thomas Hospitals, London UK.

- Mr. Mahmoud Salam: is a senior clinical research coordinator at the Ministry of National Guard Health Affairs. Riyadh, Kingdom of Saudi Arabia

\section{Ethics approval and consent to participate}

A self-explanatory letter of invitation to participate was presented to each of the participants. All participants had given written informed consents for their participation in the research presented in this manuscript with full knowledge of the possible risks and benefits of participation. Participants consented by ticking "agree", indicating their agreement to provide their feedback for this research study. Study was approved by the Institutional Review Board of the Saudi Ministry of National Guard Health Affairs, Riyadh, Saudi Arabia (Protocol \# RC13/036). This study followed the recommendations of the International Conference on Harmonization for Good Clinical Practice (ICH-GCP)

\section{Consent for publication}

Not applicable.

\section{Competing interests}

The authors declare that they have no competing interests

\section{Publisher's Note}

Springer Nature remains neutral with regard to jurisdictional claims in published maps and institutional affiliations.

\section{Author details}

'Department of Health Systems Management, College of Public Health and Health Informatics, King Abdullah International Medical Research Center, King Saud bin Abdulaziz University for Health SciencesMinistry of the National Guard Health Affairs, Riyadh, Saudi Arabia. ${ }^{2}$ Primary Care and Public Health Department, School of Public Health, Imperial College, London, UK. ${ }^{3}$ Division of Population and Patient Health, King's College London Dental Institute at Guy's, King's College and St. Thomas Hospitals, London, UK. ${ }^{4}$ Department of Community Dentistry, King Saud bin Abdulaziz University, Riyadh, Saudi Arabia. ${ }^{5}$ Science and Technology Unit, King Abdullah International Medical Research Center, King Saud bin Abdulaziz University for Health Sciences, King Abdulaziz Medical City, Ministry of National Guard - Health Affairs, PO 22490, (Mail Code 1515), Riyadh 11426, Saudi Arabia.

Received: 10 August 2018 Accepted: 29 November 2018

Published online: 10 December 2018

\section{References}

1. Barton A. Patient safety and quality: an evidence-based handbook for nurses. AORN J. 2009:90(4):601-2.

2. Aspden P, Corrigan JM, Wolcott J, Erickson SM. Committee on data standards for patient safety." patient safety: achieving a new standard for care.". Washington, DC: Institute of Medicine.

3. World Health Organization. World Alliance for Patient Safety Progress Report 2006-2007.

4. Wilson RM, Michel P, Olsen S, Gibberd RW, Vincent C, El-Assady R, Rasslan O, Qsous S, Macharia WM, Sahel A, Whittaker S. Patient safety in developing countries: retrospective estimation of scale and nature of harm to patients in hospital. BMJ. 2012;344:e832.

5. Nieva VF, Sorra J. Safety culture assessment: a tool for improving patient safety in healthcare organizations. BMJ Quality \& Safety. 2003;12(suppl 2): ii17-23.

6. Stavrianopoulos T. The development of patient safety culture. Health Sci J. 2012;6(2):201-211.

7. Sexton JB, Helmreich RL, Neilands TB, Rowan K, Vella K, Boyden J, Roberts PR, Thomas EJ. The safety attitudes questionnaire: psychometric properties, benchmarking data, and emerging research. BMC health services research. 2006;6(1):44.

8. Myung SJ, Shin JS, Kim JH, Roh H, Kim Y, Kim J, Lee SI, Lee JH, Kim SW. The patient safety curriculum for undergraduate medical students as a first step toward improving patient safety. J Surg Educ. 2012;69(5):659-64.

9. Tingle J. The WHO patient safety curriculum guide. Br J Nurs. 2011;20(22): 1456-7.

10. England A, Azevedo KB, Bezzina P, Henner A, McNulty JP. Patient safety in undergraduate radiography curricula: a European perspective. Radiography. 2016:22:S12-9.

11. Newell P, Harris S, Aufses A, Ellozy S. Student perceptions of medical errors: incorporating an explicit professionalism curriculum in the third-year surgery clerkship. J Surg Educ. 2008;65(2):117-9.

12. Flanagan B, Nestel D, Joseph M. Making patient safety the focus: crisis resource management in the undergraduate curriculum. Med Educ. 2004; 38(1):56-66

13. Fischer MA, Mazor KM, Baril J, Alper E, DeMarco D, Pugnaire M. Learning from mistakes. J Gen Intern Med. 2006;21(5):419-23. 
14. Leong P, Afrow J, Weber HP, Howell H. Attitudes toward patient safety standards in US dental schools: a pilot study. J Dent Educ. 2008;72(4):431-7.

15. Aboumatar HJ, Thompson D, Wu A, Dawson P, Colbert J, Marsteller J, Kent P, Lubomski LH, Paine L, Pronovost P. Development and evaluation of a 3 day patient safety curriculum to advance knowledge, self-efficacy and system thinking among medical students. BMJ Qual Saf. 2012;6(12):201-11.

16. Shaker RE, Babgi AA. Women in dentistry: a perspective on major universities in Saudi Arabia. Part 1: historical background. Saudi Dent J. 2009; 21(3):103-6

17. Saudi commission for health specialties. Accessed on September 25, 2018 at: https://twasul.info/1075690/

18. AlBaker AA, Al-Ruthia YS, AlShehri M, Alshuwairikh S. The characteristics and distribution of dentist workforce in Saudi Arabia: a descriptive crosssectional study. Saudi Pharm J. 2017;25(8):1208-16.

19. Gabrani A, Hoxha A, Simaku A, Gabrani JC. Application of the safety attitudes questionnaire (SAQ) in Albanian hospitals: a cross-sectional study. BMJ Open. 2015;5(4):e006528.

20. Carvalho RE, Arruda LP, Nascimento NK, Sampaio RL, Cavalcante ML, Costa AC. Assessment of the culture of safety in public hospitals in Brazil. Rev Lat Am Enfermagem. 2017;25.

21. Li Y, Zhao X, Zhang X, Zhang C, Ma H, Jiao M, Li X, Gao L, Hao M, Lv J, Zhao $Y$. Validation study of the safety attitudes questionnaire (SAQ) in public hospitals of Heilongiiang province, China. PLoS One. 2017:12(6):e0179486.

22. Nordén-Hägg A, Sexton JB, Kälvemark-Sporrong S, Ring L, Kettis-Lindblad Å. Assessing safety culture in pharmacies: the psychometric validation of the safety attitudes questionnaire (SAQ) in a national sample of community pharmacies in Sweden. BMC Clin Pharmacol. 2010;10(1):8.

23. Watts BV, Percarpio K, West P, Mills PD. Use of the safety attitudes questionnaire as a measure in patient safety improvement. J Patient Saf. 2010;6(4):206-9.

24. Cui Y, Xi X, Zhang J, Feng J, Deng X, Li A, Zhou J. The safety attitudes questionnaire in Chinese: psychometric properties and benchmarking data of the safety culture in Beijing hospitals. BMC Health Serv Res. 2017 Dec; 17(1):590.

25. Kristensen S, Sabroe S, Bartels P, Mainz J, Christensen KB. Adaption and validation of the safety attitudes questionnaire for the Danish hospital setting. Clin Epidemiol. 2015;7:149.

26. Hassan Abed BD, Abdalrahman Ainousa BD. Dental management of patients with inherited bleeding disorders: a multidisciplinary approach. Gen Dent. 2017 Nov.

27. Black I, Bowie P. Patient safety in dentistry: development of a candidate'never event'list for primary care. Br Dent J. 2017;222(10):782.

28. Littlewood S, Ypinazar V, Margolis SA, Scherpbier A, Spencer J, Dornan T. Early practical experience and the social responsiveness of clinical education: systematic review. BMJ. 2005 Aug 11;331(7513):387-91.

29. Gibis B, Heinz A, Jacob R, Müller $\mathrm{CH}$. The career expectations of medical students: findings of a nationwide survey in Germany. Dtsch Arztebl Int 2012 May;109(18):327.

30. Reinders JJ, Krijnen WP, Stegenga B, van der Schans CP. Perceived dentist and dental hygienist task distribution after dental and dental hygiene students' team intervention. J Dent Educ. 2017:81(4):413-9.

31. Sakaguchi RL. Facilitating preceptor and student communication in a dental school teaching clinic. J Dent Educ. 2010;74(1):36-42.

32. Sharp HM, Kuthy RA, Heller KE. Ethical dilemmas reported by fourth-year dental students. J Dent Educ. 2005;69(10):1116-22.

33. Vermeir P, Vandijck D, Degroote S, Peleman R, Verhaeghe R, Mortier E, Hallaert G, Van Daele S, Buylaert W, Vogelaers D. Communication in healthcare: a narrative review of the literature and practical recommendations. Int J Clin Pract. 2015:69(11):1257-67.

34. Raja S, Rajagopalan CF, Patel J, Van Kanegan K. Teaching dental students about patient communication following an adverse event: a pilot educational module. J Dent Educ. 2014;78(5):757-62.

35. Gupta S, Jain A, Garg S, Sood S, Kumari B. Perceptions of Indian dental hygiene students toward their profession and its relationship with their explicit self-esteem scores. Indian J Dent. 2014;5(4):202.

36. Al-Sowygh ZH, Alfadley AA, Al-Saif MI, Al-Wadei SH. Perceived causes of stress among Saudi dental students. King Saud Univ J Dent Sci. 2013;4(1):7-15.

37. Reinders JJ, Krijnen WP, Onclin P, Schans CP, Stegenga B. Attitudes among dentists and dental hygienists towards extended scope and independent practice of dental hygienists. Int Dent J. 2017:67(1):46-58.
38. Al Sweleh FS, Al Saedan AM, AI Dayel OA. Patient safety culture perceptions in the college of dentistry. Medicine. 2018:97(2):e9570.

39. Barakat NG. Interpersonal skills. Libyan J Med. 2007;2(3):152.

40. Galletta M, Portoghese I, Gonzales Cl, Melis P, Marcias G, Campagna M, Minerba L, Sardu C. Lack of respect, role uncertainty and satisfaction with clinical practice among nursing students: the moderating role of supportive staff. Acta Biomed. 2017:88(3-S):43-50.

41. Yamalik N. Patient safety and quality assurance and improvement. Indian J Dent Res. 2014:25(2):139.

\section{Ready to submit your research? Choose BMC and benefit from:}

- fast, convenient online submission

- thorough peer review by experienced researchers in your field

- rapid publication on acceptance

- support for research data, including large and complex data types

- gold Open Access which fosters wider collaboration and increased citations

- maximum visibility for your research: over $100 \mathrm{M}$ website views per year

At $\mathrm{BMC}$, research is always in progress.

Learn more biomedcentral.com/submissions 